\title{
Haematological abnormalities in mitochondrial disorders
}

\author{
Josef Finsterer $^{1}$, MD, PhD, Marlies Frank $^{2}$, MD
}

INTRODUCTION This study aimed to assess the kind of haematological abnormalities that are present in patients with mitochondrial disorders (MIDs) and the frequency of their occurrence.

METHODS The blood cell counts of a cohort of patients with syndromic and non-syndromic MIDs were retrospectively reviewed. MIDs were classified as 'definite', 'probable' or 'possible' according to clinical presentation, instrumental findings, immunohistological findings on muscle biopsy, biochemical abnormalities of the respiratory chain and/or the results of genetic studies. Patients who had medical conditions other than MID that account for the haematological abnormalities were excluded.

RESULTS A total of 46 patients ('definite' = 5; 'probable' = 9; 'possible' = 32) had haematological abnormalities attributable to MIDs. The most frequent haematological abnormality in patients with MIDs was anaemia. 27 patients had anaemia as their sole haematological problem. Anaemia was associated with thrombopenia $(n=4)$, thrombocytosis $(n=2)$, leucopenia $(n=2)$, and eosinophilia $(n=1)$. Anaemia was hypochromic and normocytic in 27 patients, hypochromic and microcytic in six patients, hyperchromic and macrocytic in two patients, and normochromic and microcytic in one patient. Among the 46 patients with a mitochondrial haematological abnormality, $78.3 \%$ had anaemia, $13.0 \%$ had thrombopenia, $8.7 \%$ had leucopenia and $8.7 \%$ had eosinophilia, alone or in combination with other haematological abnormalities.

CONCLUSION MID should be considered if a patient's abnormal blood cell counts (particularly those associated with anaemia, thrombopenia, leucopenia or eosinophilia) cannot be explained by established causes. Abnormal blood cell counts may be the sole manifestation of MID or a collateral feature of a multisystem problem.

Keywords: anaemia, leucopenia, oxidative phosphorylation, thrombocytosis, thrombopenia

\section{INTRODUCTION}

Mitochondrial disorders (MIDs) are an increasingly recognised group of mono- or multisystem metabolic disorders that manifest clinically in either syndromic or non-syndromic forms. ${ }^{(1)}$ MIDs are caused by mutations in either mitochondrial DNA (mtDNA)or nuclear DNA (nDNA)-located genes encoding subunits of respiratory chain complexes, ancillary proteins of respiratory chain complexes, transfer RNA (tRNA), ribosomal RNA (rRNA), proteins involved in the mtDNA replication machinery, the coenzyme-Q pathway, the mitochondrial transport machinery or the mitochondrial biosynthesis. ${ }^{(2)}$ MIDs frequently manifest in the central nervous system, peripheral nervous system, endocrine system, heart, retina, cochlea, liver and/or kidneys (mitochondrial multiorgan disorder syndrome [MIMODS]). ${ }^{(3)}$ MIDs rarely manifest in the gastrointestinal tract, cartilage, integument or the bone marrow (resulting in haematological abnormalities). ${ }^{(4)}$ They can be either syndromic (e.g. mitochondrial encephalomyopathy lactic acidosis and stroke-like episodes [MELAS]; Kearns-Sayre syndrome; neuropathy, ataxia and retinitis pigmentosa; Pearson

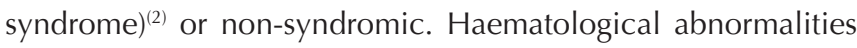
may occur together with syndromic or non-syndromic MIDs.

The present study had the following aims: (a) identify the haematological abnormalities that are present in a large cohort of patients with MIDs; (b) determine the frequency with which haematological abnormalities occur in patients with MIDs; and (c) collate information on the treatments that were applied to these patients.

\section{METHODS}

We retrospectively reviewed the blood cell counts of patients with syndromic or non-syndromic MIDs who attended the inpatient or outpatient units of the Krankenanstalt Rudolfstiftung, Austria, between May 2008 and April 2012. MID was classified as: (a) 'definite' if the clinical presentation was indicative of MID and there was biochemical or genetic evidence of a mitochondrial defect; (b) 'probable' if the clinical presentation was indicative of MID and muscle biopsy findings showed immunohistological abnormalities (e.g. cytochrome-c oxidase [COX]-negative fibres, ragged-red fibres or succinate dehydrogenase hyper-reactive fibres), or if electron microscopy showed abnormally shaped or structured mitochondria with or without paracristalline inclusions, glycogen or fat depositions; and (c) 'possible' if the clinical presentation suggested MID and instrumental findings (other than muscle biopsy) were indicative of MID. This categorisation was in accordance with guidelines of the European Federation of Neurological Sciences. ${ }^{(2)}$ Clinical findings and instrumental findings (other than those from muscle biopsy) that were suggestive of MID are summarised in Tables I and II, respectively.

Only patients who had repeated abnormal blood cell counts that could not be attributed to causes other than MID were included in the analysis. Exclusion of patients with haematological abnormalities attributed to other causes was carried out by an experienced haematologist. Patients who had anaemia due to inadequate erythrocyte production, increased erythrocyte destruction, acute or chronic bleeding, 
Table I. Symptoms and signs suggestive of a mitochondrial disorder.

\begin{tabular}{ll}
\hline Body system/organ & Clinical findings \\
\hline $\begin{array}{l}\text { Peripheral nervous } \\
\text { system }\end{array}$ & $\begin{array}{l}\text { Double vision, ptosis, ophthalmoparesis, dropped head syndrome, camptocormia, cervical spine } \\
\text { syndrome, scoliosis, limb weakness, muscular respiratory insufficiency, exercise intolerance, fatigue, } \\
\text { easy fatigability, sore muscles, myalgia, muscle cramps, sensory disturbances, sensory ataxia }\end{array}$ \\
Central nervous system & $\begin{array}{l}\text { Autism, cognitive decline, dementia, psychosis, confusion, disorientation, seizures, stroke-like } \\
\text { episodes, ischaemic stroke, hypersomnia, migraine, migraine-like headaches, cluster headache, }\end{array}$ \\
& cerebellar ataxia, movement disorder, transverse syndrome \\
Eye & Visual impairment, blurred vision, double vision, visual field defects, painful bulbs \\
Ear & Hypoacusis, tinnitus \\
Endocrine system & Short stature, sicca syndrome, hyperhidrosis, impotentia, hypogonadism, adynamia \\
Heart & Palpitations, orthopnoea, exertional dyspnoea, leg oedema, sudden cardiac death \\
Gastrointestinal tract & Dysphagia, vomiting, diarrhoea, obstipation, jaundice, colic \\
Kidney & Colic from nephrolithiasis \\
Skeleton & Arthralgia, dysmorphism \\
\hline
\end{tabular}

Note: The phenotype was taken to be indicative of MID if at least five of the listed characteristics were present

Table II. Instrumental findings indicative of a mitochondrial disorder.

\begin{tabular}{|c|c|}
\hline Body system/organ & Instrumental findings \\
\hline $\begin{array}{l}\text { Central nervous system } \\
\text { (via cerebral imaging) }\end{array}$ & $\begin{array}{l}\text { Basal ganglia calcification, focal cerebral atrophy, white matter lesions, stroke-like lesion, } \\
\text { pituitary adenoma, optic atrophy }\end{array}$ \\
\hline Eye & Pigmentary retinopathy, cataract, glaucoma, optic atrophy, prolonged visually-evoked potentials \\
\hline Serum/cerebrospinal fluid (CSF) & $\begin{array}{l}\text { Elevated serum/CSF lactate, elevated CSF protein, pleocytosis, recurrent and elevated creatine } \\
\text { kinase, elevated liver function parameters, renal insufficiency, hyperlipidaemia, hyperuricaemia }\end{array}$ \\
\hline Blood cell & Anaemia, thrombopenia, thrombocytosis, leucopenia, eosinophilia \\
\hline Heart & $\begin{array}{l}\text { Hypertrophic cardiomyopathy, dilated cardiomyopathy, noncompaction, Takotsubo syndrome, } \\
\text { arrhythmias }\end{array}$ \\
\hline Kidney & Kidney cysts, nephrolithiasis, renal failure \\
\hline Gastrointestinal tract & Parotitis, hepatopathy, pancreatitis, pancreatic cysts, liver cysts, diverticulosis, nonspecific colitis \\
\hline Endocrine system & $\begin{array}{l}\text { Osteoporosis, hypopituitarism, hypocorticism, diabetes mellitus, hypoaldosteronism, } \\
\text { hypothyroidism, hyperthyroidism, hypopituitarism, hypocorticism, hypogonadism }\end{array}$ \\
\hline Blood vessel & Atherosclerosis, stenosis, aneurysm, ectasia, dissection, rupture \\
\hline Skin & Madarosis, psoriasis, lipomatosis, lipoedema \\
\hline
\end{tabular}

Note: Instrumental findings exclude those from muscle biopsies or genetic testings

and/or fluid overload (Table III) were excluded. ${ }^{(5)}$ Patients with the following non-mitochondrial causes of thrombopenia were also excluded: (a) decreased production or increased destruction of thrombocytes; (b) drug-induced thrombopenia; and/or (c) non-classified thrombopenia (Table IV). ${ }^{(5)}$ Primary and secondary causes of thrombocytosis were excluded before thrombocytosis was attributed to the underlying MID (Table V). Patients with leucopenia or neutropenia resulting from decreased production, increased destruction and drugs known to be causative were excluded (Table VI). Eosinophilia was attributed to the underlying MID only if allergy, helminthiasis, infections with protozoas, chronic intoxication, malignancy (lymphoma), systemic lupus erythematosus, vasculitis (Churg-Strauss), eosinophilic neuromuscular disorders, cholesterol embolism, coccidoidomycosis (valley fever) and drug use (e.g. natalizumab) were excluded.

\section{RESULTS}

During the four-year observational period, 444 patients were diagnosed with MID - 15 (3.4\%) 'definite', 54 (12.2\%) 'probable' and $375(84.5 \%)$ 'possible' MIDs. Stratification of the patients and the results of their haematological investigations are summarised in Table VII. The results of 26 of the 444 patients who underwent haematological investigations were not available. Among the remaining 418 patients, 252 patients had normal blood cell counts and 166 patients had abnormal counts. In these 166 patients, 120 (2 'definite', 9 'probable' and 109 'possible' MIDs) had haematological abnormalities attributed to causes other than MID. Thus, 46 patients (30 female, 16 male; age 18-91 years) had haematological abnormalities attributable to MID. These 46 patients (5 'definite', 9 'probable' and 32 'possible' MIDs) were included in the data analysis.

Of the 46 patients with MID-related haematological abnormalities, 27 (2 'definite', 3 'probable' and 22 'possible' MIDs) had anaemia only. Anaemia was associated with thrombopenia in four patients, thrombocytosis in two patients, leucopenia in two patients, and eosinophilia in one patient. Other sole haematological abnormalities attributable to MID included: erythrocytosis $(n=1)$; pancytopenia $(n=1)$; polyglobulia $(n=1)$; thrombopenia $(n=2)$; leucopenia $(n=2)$; and eosinophilia 
Table III. Causes of anaemia that were excluded before it was attributed to a mitochondrial disorder.

\begin{tabular}{|c|c|}
\hline Category & Cause \\
\hline \multirow{8}{*}{$\begin{array}{l}\text { Inadequate production } \\
\text { (low reticulocyte } \\
\text { production index) }\end{array}$} & $\begin{array}{l}\text { 1. No clinical findings* consistent with haemolysis or blood loss: pure disorder of production }(\mathrm{MCV}>100 \text {, } \\
80-100 \text { or }<80 \mathrm{fL})\end{array}$ \\
\hline & $\begin{array}{l}\text { 2. Clinical findings* and abnormal MCV (> } 100 \text { or }<80 \mathrm{fL} \text { ): haemolysis, or loss and chronic disorder of } \\
\text { production (e.g. sickle cell anaemia with superimposed iron deficiency, chronic gastric bleeding with } \\
\text { B12 and folate deficiency, and other instances of anaemia with more than one cause) }\end{array}$ \\
\hline & $\begin{array}{l}\text { 3. Clinical findings* and normal MCV ( } 80-100 \mathrm{fL}) \text { means acute haemolysis or loss without adequate time } \\
\text { for bone marrow production to compensate (e.g. bone marrow failure or anaemia of chronic disease, } \\
\text { with superimposed or related haemolysis or blood loss). }\end{array}$ \\
\hline & Disturbance of proliferation or differentiation of stem cells: \\
\hline & $\begin{array}{l}\text { Pure red cell aplasia, aplastic anaemia affecting all kinds of blood cells (Fanconi anemia), renal } \\
\text { insufficiency (insufficient erythropoietin production), endocrine disorders }\end{array}$ \\
\hline & Disturbance of proliferation or maturation of erythroblasts: \\
\hline & $\begin{array}{l}\text { Pernicious anaemia (reduced production of intrinsic factor), folic acid deficiency, diminished } \\
\text { erythropoietin response to declining haematocrit (premature infants), iron deficiency, thalassaemia, } \\
\text { congenital dyserythropoietic anaemia, renal insufficiency } \\
\text { Other mechanisms of impaired RBC production: }\end{array}$ \\
\hline & $\begin{array}{l}\text { Myelophthisis (replacement of bone marrow by other materials), myelodysplastic syndrome, chronic } \\
\text { inflammation }\end{array}$ \\
\hline \multirow{5}{*}{$\begin{array}{l}\text { Increased RBC destruction } \\
\text { and/or loss (haemolysis, } \\
\text { blood loss, normal RBC } \\
\text { production, normal } \\
\text { reticulocyte production } \\
\text { index [appropriate } \\
\text { response to anaemia]) }\end{array}$} & Intrinsic (intracorpuscular) abnormalities: \\
\hline & $\begin{array}{l}\text { Hereditary spherocytosis (cell membrane defect), hereditary elliptocytosis (defect in skeleton proteins), } \\
\text { abetalipoproteinaemia (defect membrane lipids), pyruvate kinase, hexokinase deficiency (defect } \\
\text { glycolysis), glucose-6-phosphate dehydrogenase deficiency, glutathione synthesis deficiency, } \\
\text { haemoglobinopathies (sickle cell anaemia, unstable haemoglobin), paroxysmal nocturnal haemoglobinuria } \\
\text { Extrinsic (extracorpuscular) abnormalities: }\end{array}$ \\
\hline & Antibody-mediated, warm autoimmune haemolytic anaemia (Immunoglobulin G attack against RBCs) \\
\hline & Cold agglutinine haemolytic (IgM-mediated): \\
\hline & $\begin{array}{l}\text { Rh disease (haemolytic disease of the newborn), transfusion reaction, mechanical trauma to RBCs, } \\
\text { microangiopathy, infections (malaria), cardiac surgery }\end{array}$ \\
\hline Blood loss & $\begin{array}{l}\text { Frequent blood sampling, trauma, surgery, gastrointestinal lesions, gynaecological disturbances, } \\
\text { menstruation }\end{array}$ \\
\hline Fluid overload & Hypervolaemia, pregnancy \\
\hline
\end{tabular}

*Haemolysis on peripheral blood smear, jaundice or elevated lactate dehydrogenase (indicating cell destruction), clinical signs of bleeding (e.g. guaiac-positive stool, radiographic findings or frank bleeding). MCV: mean corpuscular volume; RBC: red blood cell

Table IV. Causes of thrombopenia that were excluded before it was attributed to a mitochondrial disorder.

\begin{tabular}{ll}
\hline Category & Cause \\
\hline Decreased production & Vitamin B12 deficiency, folic acid deficiency, leukaemia, megalodysplastic syndrome, decreased \\
& thrombopoietin production in liver, sepsis, dengue fever, hereditary (congenital amegakaryocytic \\
& thrombopenia, thrombopenia absent radius syndrome, Fanconi anaemia, Bernard-Soulier syndrome, \\
& May-Hegglin anomaly, Grey platelet syndrome, Alport syndrome, Wiskott-Aldrich syndrome) \\
& Idiopathic thrombopenic purpura, thrombocytic thrombopenic purpura, haemolytic uremic syndrome, \\
Increased destruction & disseminated intravascular coagulation, paroxysmal nocturnal haemoglobinuria, anti-phospholipid syndrome, \\
& dengue fever, HIV-associated thrombopenia \\
& Myelosuppression (e.g. valproic acid, methotrexate, carboplatin, interferon, isotretinoin, other chemotherapy \\
Medication-induced & abciximab) \\
& Snake bites, onyalai, oils containing erucic acid (Lorenzo's oil, mustard oil) \\
\hline
\end{tabular}

$(\mathrm{n}=3)$. None of the patients had thrombocytosis as the sole haematological problem. Alone, or in combination, anaemia was present in 36 patients, thrombopenia in six patients, leucopenia in four patients, erythrocytosis in one patient, thrombocytosis in two patients and eosinophilia in four patients. Among patients with anaemia, the reticulocyte count was available for three patients and elevated in one patient (data not shown). Anaemia was hypochromic and normocytic in 27 patients, hypochromic and microcytic in six patients, hyperchromic and macrocytic in two patients, and normochromic and microcytic in one patient (Fig. 1).

Anaemia was the most frequent haematological abnormality among patients who had haematological abnormalities attributable to MID. Anaemia attributable to MID was found in $8.6 \%$ of the 418 patients who had available blood cell counts, while thrombopenia and leucopenia attributable to MID was found in $1.4 \%$ and $1.0 \%$ of the 418 patients, respectively. Among the 46 patients who had haematological abnormalities attributable 
Table V. Causes of thrombocytosis that were excluded before it was attributed to a mitochondrial disorder.

\begin{tabular}{ll}
\hline Category & Cause \\
\hline Primary & Myelodysplastic disease, chronic myelogenous \\
(essential) & leukaemia, polycythemia vera, myelofibrosis \\
Secondary & Inflammation, surgery, hyposplenism, \\
(reactive) & splenectomy, asplenia, anaemia or haemorrhage, \\
& overmedication to treat thrombocytopenia, \\
& Kawasaki disease, soft tissue sarcoma, \\
& osteosarcoma, dermatitis, inflammatory \\
& bowel disease, rheumatoid arthritis, nephritis, \\
& nephrotic syndrome, bacterial disease \\
\hline
\end{tabular}

Table VI. Causes of leucopenia that were excluded before it was attributed to a mitochondrial disorder.

\begin{tabular}{ll}
\hline Category & Cause \\
\hline Decreased & Radiation, infection (e.g. human \\
production & $\begin{array}{l}\text { immunodeficiency virus infection, typhoid } \\
\text { disease, malaria, tuberculosis, dengue, Rickettsial } \\
\text { infection, psittacosis and sepsis), myelofibrosis, } \\
\end{array}$ \\
& $\begin{array}{l}\text { aplastic anaemia, malignancy (lymphoma), folate, } \\
\text { copper, zinc deficiency }\end{array}$ \\
Increased & Hypersplenism, immunological \\
destruction & disease (e.g. systemic lupus erythematosus) \\
Drugs & Clozapine, bupropion, minocycline, valproic \\
& acid, lamotrigine, cyclosporine, tacrolimus, \\
& sirolimus, mycophenolate mofetil, interferon, \\
& chemotherapy (particularly neutropenia)
\end{tabular}

to MID, $78.3 \%$ had anaemia, $13.0 \%$ had thrombopenia, $8.7 \%$ had leucopenia and $8.7 \%$ had eosinophilia, alone or in combination with other haematological abnormalities (Fig. 2). None of the patients had undergone a bone marrow biopsy and none of the patients with thrombopenia had impaired blood coagulation.

Except for anaemia, the haematological abnormalities found in the 46 patients did not require medical treatment. Anaemia was resistant to treatment with folic acid, pyridoxine, vitamin B12 and iron in all 36 patients, while one patient required blood transfusions. Erythropoietin was attempted in one patient, but it did not yield long-term success. None of the patients with thrombopenia required drug treatment or infusion with thrombocyte concentrates. A patient with thrombocytosis received hydroxyurea from time to time.

\section{DISCUSSION}

The present study shows that haematological abnormalities in syndromic and non-syndromic MIDs frequently include anaemia, thrombopenia, leucopenia and eosinophilia, and less frequently include thrombocytosis, erythrocytosis, polyglobulia, and pancytopenia, in combination or alone. The most common of these abnormalities was anaemia, followed by thrombopenia and leucopenia. Treatment for anaemia, which included vitamin and iron substitution, blood transfusions and/or erythropoietin, was applied only in some patients.

Haematological abnormalities are well-known dominant or collateral features of MIDs. ${ }^{(4)}$ Syndromic MIDs with haematological manifestations include: (a) Pearson syndrome,

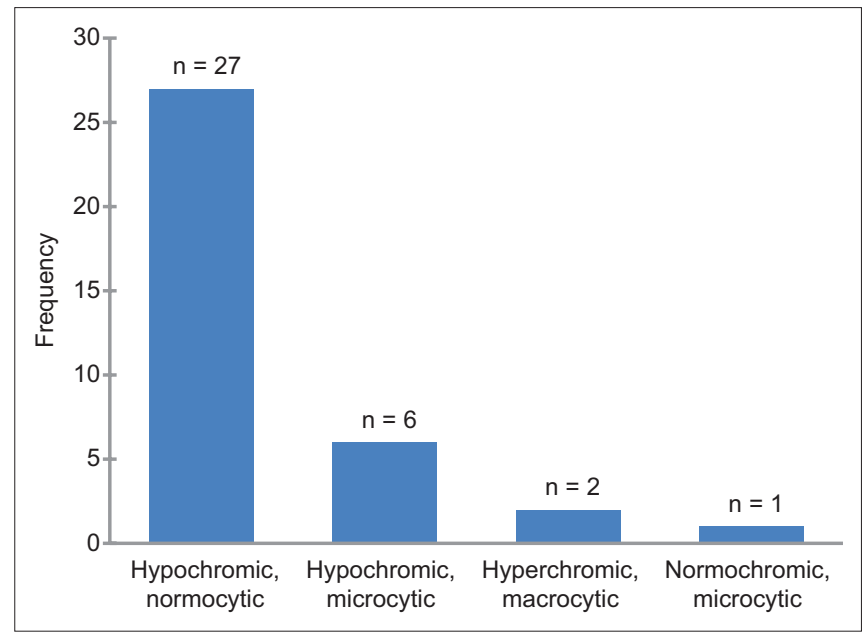

Fig. 1 Bar graph shows the frequency of anaemia types among the 46 patients with haematological abnormalities attributable to mitochondrial disorder.

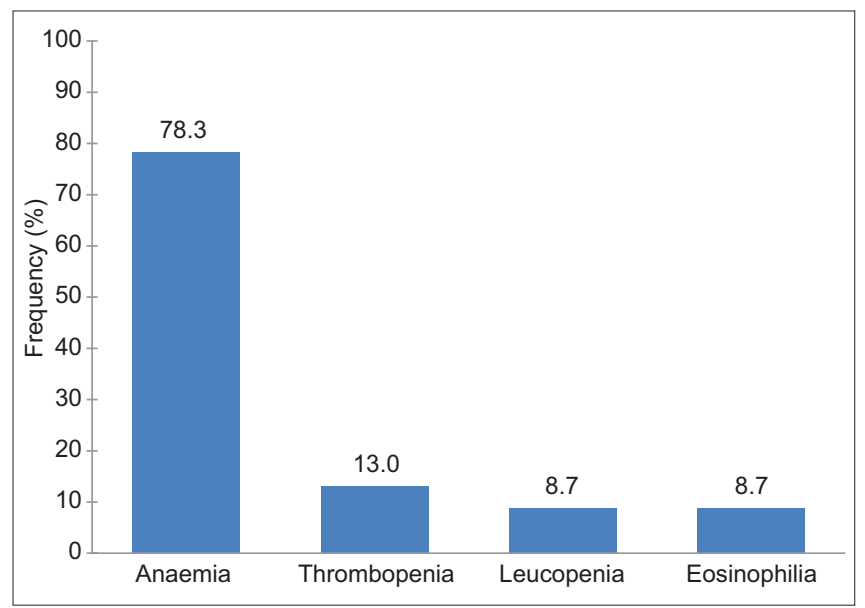

Fig. 2 Bar graph shows the frequency of anaemia, thrombopenia, leucopenia and eosinophilia among the 46 patients with haematological abnormalities attributable to mitochondrial disorder.

a rare congenital disorder with severe sideroblastic anaemia or pancytopenia and exocrine pancreas insufficiency; ${ }^{(6)}$ occasionally, the kidneys, liver, guts or skin are affected; (b) Kearns-Sayre syndrome, a disorder characterised by onset at $<20$ years, ophthalmoplegia, pigmentary retinopathy, conduction block, cerebellar ataxia, increased cerebrospinal fluid protein and/or sideroblastic anaemia; ${ }^{(7)}$ (c) Barth syndrome, a disorder characterised by noncompaction, mitochondrial myopathy and neutropenia; ${ }^{\left({ }^{(8)}\right.}$ (d) autosomal recessive mitochondrial myopathy, lactic acidosis and sideroblastic anaemia (MLASA); ${ }^{(9,10)}$ (e) X-linked sideroblastic anaemia (XLSA), the most common type of sideroblastic anaemia; ${ }^{(11,12)}$ and (f) X-linked sideroblastic anaemia with ataxia (XLSA-A)(12) ${ }^{(T a b l e ~ V I I I) . ~}{ }^{(4)}$ The following syndromic MIDs have also been described in association with haematological manifestations in single cases: (a) Leighsyndrome; ${ }^{(13)}$ (b) MELAS; (14) and (c) Leber's hereditary optic neuropathy ${ }^{(15)}$ (Table I). Anaemia, leucopenia, thrombopenia, eosinophilia and pancytopenia have also been reported in some non-syndromic MIDs, with and without affecting tissues other than the muscle (Table VIII). ${ }^{(16-19)}$ 
Table VII. Stratification and results of haematological investigations of patients with mitochondrial disorders (MIDs).

\begin{tabular}{|c|c|c|c|}
\hline \multirow[t]{2}{*}{ Variable } & \multicolumn{3}{|c|}{ No. of MID patients (\%) } \\
\hline & 'Definite' & 'Probable' & 'Possible' \\
\hline Patients screened $(n=444)$ & $15(3.4)$ & $54(12.2)$ & $375(84.5)$ \\
\hline Absence of blood cell counts $(n=26)$ & $3(11.5)$ & $2(7.7)$ & $21(80.8)$ \\
\hline Normal blood cell counts $(n=252)$ & NC & NC & NC \\
\hline HA not due to MID $(n=120)$ & $2(1.7)$ & $9(7.5)$ & $109(90.8)$ \\
\hline Anaemia $(n=27)$ & $2(7.4)$ & $3(11.1)$ & $22(81.5)$ \\
\hline Anaemia + thrombopenia $(n=4)$ & $1(25.0)$ & $2(50.0)$ & $1(25.0)$ \\
\hline Anaemia + thrombocytosis $(n=2)$ & $0(0)$ & $0(0)$ & $2(100.0)$ \\
\hline Anaemia + leucopenia $(n=2)$ & $0(0)$ & $2(100.0)$ & $0(0)$ \\
\hline Anaemia + eosinophilia $(n=1)$ & $0(0)$ & $1(100.0)$ & $0(0)$ \\
\hline Erythrocytosis $(n=1)$ & $0(0)$ & $1(100.0)$ & $0(0)$ \\
\hline Polyglobulia $(n=1)$ & $0(0)$ & $0(0)$ & $1(100.0)$ \\
\hline Leucopenia $(n=2)$ & $1(50.0)$ & $0(0)$ & $1(50.0)$ \\
\hline Eosinophilia $(n=3)$ & $0(0)$ & $0(0)$ & $3(100.0)$ \\
\hline Thrombopenia $(n=2)$ & $1(50.0)$ & $0(0)$ & $1(50.0)$ \\
\hline \multicolumn{4}{|l|}{ Anaemia (sole or collateral) } \\
\hline Hypochromic, normocytic $(n=27)$ & NC & NC & NC \\
\hline Hypochromic, microcytic $(n=6)$ & NC & $\mathrm{NC}$ & NC \\
\hline Hyperchromic, macrocytic $(n=2)$ & NC & NC & NC \\
\hline Normochromic, microcytic $(n=1)$ & NC & NC & NC \\
\hline
\end{tabular}

HA: haematological abnormality; NC: not counted

Table VIII. Mitochondrial disorders associated with haematological abnormalities.

\begin{tabular}{|c|c|c|c|}
\hline MID & Haematological abnormality & Gene & Study \\
\hline \multicolumn{4}{|l|}{ Syndromic } \\
\hline Pearson syndrome & Anaemia, pancytopenia & mtDNAdel & Manea et $\mathrm{al}^{(6)}$ \\
\hline Kearns-Sayre syndrome & Anaemia & mtDNAdel & Leung et al,(7) Williams et $\mathrm{al}^{(22)}$ \\
\hline Barth syndrome & Neutropenia & Tafazzine & van Raam \& Kuijpers ${ }^{(8)}$ \\
\hline MLASA syndrome & Anaemia & YARS2. PUS1 & Riley et al, ${ }^{(10)}$ Sasarman et al ${ }^{(35)}$ \\
\hline XLSA with ataxia & Anaemia & $\mathrm{ABCB} 7$ & Fontenay et $\mathrm{al}^{(12)}$ \\
\hline Leigh-syndrome & Anaemia & Numerous & Nagashima et al ${ }^{(13)}$ \\
\hline LHON & Anaemia & Several & Pott \& Wong(15) \\
\hline MELAS & Anaemia, thrombocytosis & Not reported & Finsterer ${ }^{(14)}$ \\
\hline TRMA & Megaloblastic anaemia & SLC19A2 & Fleming, ${ }^{(36)}$ Cazzola \& Invernizzi ${ }^{(37)}$ \\
\hline \multicolumn{4}{|l|}{ Non-syndromic } \\
\hline Anaemia & Sideroblastic anaemia & SLC25A38 & Kannengiesser et $\mathrm{al}^{(17)}$ \\
\hline mtDNA depletion & Anaemia, thrombopenia, T-cells $\downarrow$ & POLG1 & Reichenbach et $\mathrm{al}^{(28)}$ \\
\hline Congenital neutropenia & Neutropenia & HAX-1 & Boztug et $\mathrm{al}^{(32)}$ \\
\hline LE, cerebral calcification & Anaemia & DARS2 & Orcesi et al ${ }^{(18)}$ \\
\hline MP, hCMP, SLE & Anaemia, thrombopenia & CII, IV defect & Van Hove et $\mathrm{al}^{(25)}$ \\
\hline Haemolytic uremic syndrome & Anaemia, thrombopenia & CII-defect & Micheletti et al(19) \\
\hline Myopathy, lactacidosis & Anaemia & Not reported & Inbal et $\mathrm{al}^{(16)}$ \\
\hline
\end{tabular}

AR-SA: autosomal-recessive sideroblastic anaemia; hCMP: hypertrophic cardiomyopathy; LE: leucoencephalopathy; LHON: Leber's hereditary optic neuropathy; MELAS: mitochondrial encephalomyopathy, lactic acidosis and stroke-like episodes; MLASA: autosomal recessive mitochondrial myopathy, lactacidosis and sideroblastic anaemia; MP: myopathy; mtDNA: mitochondrial DNA; SLE: stroke-like episode; TRMA: thiamine-responsive megaloblastic anaemia;

Haematological abnormalities occur in MIDs because of the involvement of mitochondria in haematopoiesis (through oxidative phosphorylation, heme synthesis, iron metabolism, iron-sulfur [Fe-S] cluster biogenesis and apoptosis). ${ }^{(12)}$ Mutations in the ALAS2 gene, which encodes the 5-aminolevulinatesynthase-2 (ALAS-2) isoform that catalyses the first step in 
heme synthesis in the mitochondrial matrix, lead to ineffective erythropoiesis, a characteristic feature of XLSA. Mutations in the adenosine triphosphate-binding cassette protein B7 (ABCB7), which is identified in XLSA-A, disrupt the maturation of cytosolic Fe-S clusters, leading to mitochondrial iron accumulation. ${ }^{(12)}$ Although it is unknown why tafazzin mutations (which lead to Barth-syndrome) are associated with leucopenia, the involvement of tafazzin in the cardiolipin metabolism process may be a possible cause. ${ }^{(8)}$ Mutations in the YARS-2 gene, which codes for mitochondrial tyrosyl-tRNA synthetase, causes reduced aminoacylation, resulting in decreased protein synthesis, respiratory chain dysfunction and MLASA. ${ }^{(10)}$ Large-scale deletions in the mtDNA, whose integrity depends on a specific DNA polymerase, are hallmarks of Pearson and Kearns-Sayre syndromes. In the early stages of acquired myelodysplastic syndromes, exacerbation of physiological pathways involving caspases and mitochondria in erythroid differentiation leads to abnormal activation of a mitochondrion-mediated apoptotic cell death pathway. ${ }^{(12)} \mathrm{mtDNA}$ deletions may induce abnormalities in erythropoiesis by causing haematopoietic cell-specific respiration defects. ${ }^{(20)}$ The high frequency of haematological abnormalities in patients who had definite MID in our study may indicate that haematological abnormalities are indeed a phenotypic feature of MIDs.

In the present study, anaemia was the most frequent haematological abnormality in syndromic and non-syndromic MIDs. This finding is consistent with other reports, where anaemia was also more frequent in MIDs than abnormalities in thrombocyte or leucocyte count (either as the sole, dominant or collateral feature of the phenotype) (Table VIII). ${ }^{(17,21)}$ Although anaemia as a sole manifestation of MID was not seen in the present study, it has been previously reported in a patient carrying a large-scale mtDNA deletion (encompassing the genes ATPase6, COX-III, ND3, ND4, ND5, ND6 and cytb). ${ }^{(21)}$ In another case, a mutation in the nDNA-located gene, SLC25A38, which encodes a carrier of the inner mitochondrial membrane, resulted in isolated non-syndromic microcytic, hypochromic and sideroblastic anaemia (autosomal recessive pyridoxinerefractory sideroblastic anaemia). ${ }^{(17)}$ Anaemia as the sole feature of the phenotype is also characteristic of XLSA. ${ }^{(12)}$ Anaemia as a collateral feature of the phenotype of syndromic MIDs has been reported in Pearson syndrome, Kearns-Sayre syndrome, MLASA, XLSA-A and Leigh syndrome. ${ }^{(6,10,12,13,15,22)}$ The syndromic MID most frequently associated with hematological abnormalities is Pearson syndrome. ${ }^{(22,23)}$ Haematological abnormalities are most commonly the cause of early death in patients with Pearson syndrome. ${ }^{(24)}$ Anaemia in Pearson or Kearns-Sayre syndrome is sideroblastic and usually associated with leucopenia or pancytopenia. While anaemia was never the sole phenotypic feature of MID in the present study, it was always present among other phenotypic features of MID (Table VII). ${ }^{(18,22,23)}$ In nonsyndromic MIDs, anaemia has been described as a phenotypic feature in patients with leucoencephalopathy and intracerebral calcifications due to a DARS2 mutation. ${ }^{(18)}$ Anaemia, together with thrombopenia, has been reported in a 40-year-old man with a combined complex II and IV defect, who also presented with myopathy, renal insufficiency, hypertrophic cardiomyopathy, a stroke-like episode and lactacidosis. ${ }^{(25)}$ Anaemia associated with thrombopenia can also be a feature of haemolytic uraemic syndrome due to a complex II defect. ${ }^{(19)}$ Although rare, anaemia can be an initial manifestation of a multisystem MID (i.e. MIMODS). ${ }^{(21)}$

Sideroblastic anaemia is heterogeneous and characterised by excess iron accumulation in the mitochondria of erythroblasts. ${ }^{(11,26)}$ The morphological hallmark of sideroblastic anaemia is the ring sideroblast, a pathological erythroid precursor containing an excessive amount of non-heme iron deposits in the mitochondria with perinuclear distribution, generating a ring appearance. ${ }^{(26)}$ Sideroblastic anaemia may be hereditary or acquired. Hereditary sideroblastic anaemia may be caused by mutations in nDNA-located genes such as ALAS2, ABCB7, GRLX5, SLC25A38, SF3B1, JAK2, TET2, MPLW515 and YARS2, or by large mtDNA deletions. ${ }^{(26)}$ Acquired sideroblastic anaemia can be primary (refractory anaemia with ring sideroblasts [RARS]), representing a subtype of myelodysplastic syndrome, or secondary (due to drugs, toxins, copper deficiency or malignancy). Ring sideroblasts may develop as a result of defective heme synthesis in erythroblasts (as in XLSA), a defect in the Fe-S cluster assembly, release of $\mathrm{Fe}-\mathrm{S}$ protein precursor from the mitochondria (as in XLSA-A) or defective intracellular iron metabolism in erythroid cells (as in RARS). ${ }^{(11,26)}$

Thrombopenia has been occasionally reported in patients with MIDs. Although thrombopenia is more frequently seen in Pearson syndrome, ${ }^{(6)}$ it can also occur in Kearns-Sayre syndrome. ${ }^{(27)}$ In non-syndromic MIDs, thrombopenia has been reported in a boy who had a mtDNA depletion syndrome due to a POLG1 mutation; he also presented with immunodeficiency with severe recurrent infections, anaemia, automutilation and cerebral abnormalities. ${ }^{(28)}$ Thrombopenia was also a phenotypic feature in a 40-year-old woman with myopathy, renal insufficiency, cardiomyopathy, stroke-like episodes and anaemia. ${ }^{(25)}$ The present study provides evidence that thrombopenia is a less frequent phenotypic feature of MIDs than expected. Thrombopenia particularly occurs in patients with non-syndromic MIDs. Since some patients with MIDs develop hypothyroidism (a common cause of thrombopenia), (29) thyroid disorders and other possible causes (Table IV) should be excluded before thrombopenia is attributed to an MID. Thrombocytosis is a rare phenotypic feature of MIDs. To the best of our knowledge, it has only been reported in one patient with MELAS syndrome. ${ }^{(14)}$ The present study also provided evidence that there is a low prevalence of thrombocytosis in MIDs.

Leucopenia as the sole haematological abnormality of MID has been reported in syndromic and non-syndromic MIDs. ${ }^{(30)}$ Leucopenia in the form of neutropenia is commonly seen in patients with Barth syndrome, where neutropenia is the 
hallmark of the phenotype. ${ }^{(31)}$ Neutropenia does not necessarily result in an increased rate of infections. Leucopenia (including neutropenia), together with thrombopenia, may also be a feature of Kearns-Sayre syndrome. ${ }^{(27)}$ One of the possible causes of severe congenital neutropenia in non-syndromic MID is mutation in the gene encoding the mitochondrial protein $\mathrm{HAX}-1$, a regulator of calcium signalling and apoptosis progression. ${ }^{(32)}$ Neutropenia in non-syndromic MID may also be caused by mtDNA depletion due to a POLG1 mutation, which may manifest as fatal, neonatal-onset T-cell immunodeficiency that is associated with chronic infection. ${ }^{(28)}$ Leucopenia as a feature of pancytopenia has been reported in patients with Pearson and Kearns-Sayre syndromes. ${ }^{(27,33)}$

Eosinophilia is a rare phenotypic feature of MIDs that has rarely been reported in the literature. Finsterer and Höger reported eosinophilia in a 65-year-old woman (who had pituitary adenoma, basal ganglia calcification, tetraspasticity, restless legs, hypoacusis, tinnitus, atrial fibrillation, myopathy, polyneuropathy, polyarthralgia, osteoporosis, hyponatraemia and hyperlipidaemia), which was attributed to non-syndromic, multisystem MID after a muscle biopsy and exclusion of ChurgStrauss syndrome. ${ }^{(34)}$ She also presented with a history of recurrent thrombopenia in addition to eosinophilia. MID was diagnosed based on the patient's clinical presentation and muscle biopsy findings (single ragged-red fibres, COX-negative fibres and slight increase in glycogen). ${ }^{(34)}$ However, in the present study, eosinophilia attributable to MID was not infrequent; it was found in 11 patients, four of whom also had other haematological abnormalities.

Therapeutic options depend on the type of blood cell abnormality. Options include substitution of iron, pyridoxine (SLC25A38), blood transfusions, thrombocyte transfusions, administration of erythropoietin, hydroxylurea, leucocyte stimulation factor and haematopoetic stem cell transplantation (i.e. bone marrow transplantation) in patients with Pearson syndrome. ${ }^{(17,24)}$ In the present study, the application of anaemia treatment to the patients was largely ineffective.

To conclude, MID should be considered a cause of abnormal blood cell count, especially if the abnormality cannot be explained by established causes or there is unexplained anaemia, thrombopenia, thrombocytosis, leucopenia or eosinophilia (alone or in combination). Abnormal blood cell counts may be the sole manifestation of an MID but, more frequently, it is part of a multisystem problem. Haematological abnormalities may be the initial manifestation of an MID.

\section{REFERENCES}

1. Finsterer J. Inherited mitochondrial disorders. Adv Exp Med Biol 2012; 942:187-213.

2. Finsterer J, Harbo HF, Baets J, et al; European Federation of Neurological Sciences. EFNS guidelines on the molecular diagnosis of mitochondrial disorders. Eur J Neurol 2009; 16:1255-64.

3. McFarland R, Taylor RW, Turnbull DM. A neurological perspective on mitochondrial disease. Lancet Neurol 2010; 9:829-40.

4. Finsterer J. Hematological manifestations of primary mitochondrial disorders. Acta Haematol 2007; 118:88-98.

5. Kjeldsberg CR. Practical Diagnosis of Hematologic Disorders: 3rd Edition.
Chicago, IL: American Society for Clinical Pathology, 1995.

6. Manea EM, Leverger G, Bellmann F, et al. Pearson syndrome in the neonatal period: two case reports and review of the literature. J Pediatr Hematol Oncol 2009; 31:947-51.

7. Leung TF, Hui J, Shoubridge E, et al. Aplastic anaemia in association with Kearns-Sayre syndrome. J Inherit Metab Dis 1999; 22:86-7.

8. van Raam BJ, Kuijpers TW. Mitochondrial defects lie at the basis of neutropenia in Barth syndrome. Curr Opin Hematol 2009; 16:14-9.

9. Fernandez-Vizarra E, Berardinelli A, Valente L, Tiranti V, Zeviani M. Nonsense mutation in pseudouridylate synthase 1 (PUS1) in two brothers affected by myopathy, lactic acidosis and sideroblastic anaemia (MLASA). J Med Genet 2007; 44:173-800.

10. Riley LG, Cooper S, Hickey P, et al. Mutation of the mitochondrial tyrosyl-tRNA synthetase gene, YARS2, causes myopathy, lactic acidosis, and sideroblastic anaemia--MLASA syndrome. Am J Hum Genet 2010; 87:52-9.

11. Harigae H, Furuyama K. Hereditary sideroblastic anaemia: pathophysiology and gene mutations. Int J Hematol 2010; 92:425-31.

12. Fontenay M, Cathelin S, Amiot M, Gyan E, Solary E. Mitochondria in hematopoiesis and hematological diseases. Oncogene 2006; 25:4757-67.

13. Nagashima T, Mori M, Katayama K, et al. Adult Leigh syndrome with mitochondrial DNA mutation at 8993. Acta Neuropathol 1999; 97:416-22.

14. Finsterer J. Chronic anaemia as a manifestation of MELAS syndrome. Rev Invest Clin 2011; 63:100-3.

15. Pott JW, Wong KH. Leber's hereditary optic neuropathy and vitamin B12 deficiency. Graefes Arch Clin Exp Ophthalmol 2006; 244:1357-9.

16. Inbal A, Avissar N, Shaklai M, et al. Myopathy, lactic acidosis, and sideroblastic anaemia: a new syndrome. Am J Med Genet 1995; 55:372-8.

17. Kannengiesser C, Sanchez M, Sweeney M, et al. Missense SLC25A38 variations play an important role in autosomal recessive inherited sideroblastic anaemia. Haematologica 2011; 96:808-13.

18. Orcesi S, La Piana R, Uggetti C, et al. Spinal cord calcification in an early-onset progressive leukoencephalopathy. J Child Neurol 2011; 26:876-80.

19. Micheletti MV, Lavoratti G, Gasperini S, Donati MA, Pela I. Hemolytic uremic syndrome and rhabdomyolysis in a patient with succinate coenzyme Q reductase (complex II) deficiency. Clin Nephrol 2011; 76:68-73.

20. Inoue S, Yokota M, Nakada K, Miyoshi H, Hayashi J. Pathogenic mitochondrial DNA-induced respiration defects in hematopoietic cells result in anaemia by suppressing erythroid differentiation. FEBS Lett 2007; 581:1910-6

21. Binder V, Steenpass L, Laws HJ, Ruebo J, Borkhardt A. A novel mtDNA large-scale mutation clinically exclusively presenting with refractory anaemia: is there a chance to predict disease progression? J Pediatr Hematol Oncol 2012; 34:283-92.

22. Williams TB, Daniels M, Puthenveetil G, et al. Pearson syndrome: unique endocrine manifestations including neonatal diabetes and adrenal insufficiency. Mol Genet Metab 2012; 106:104-7.

23. Cammarata-Scalisi F, López-Gallardo E, Emperador S, et al. [Pearson syndrome. Case report]. Invest Clin 2011; 52:261-7. Spanish.

24. Tumino M, Meli C, Farruggia P, et al. Clinical manifestations and management of four children with Pearson syndrome. Am J Med Genet A 2011; 155A:3063-6.

25. Van Hove JL, Shanske S, Ciacci F, et al. Mitochondrial myopathy with anaemia, cardiomyopathy, and lactic acidosis: a distinct late onset mitochondrial disorder. Am J Med Genet 1994; 51:114-20.

26. Sheftel AD, Richardson DR, Prchal J, Ponka P. Mitochondrial iron metabolism and sideroblastic anaemia. Acta Haematol 2009; 122:120-33.

27. Simonsz HJ, Bärlocher K, Rötig A. Kearns-Sayre's syndrome developing in a boy who survived pearson's syndrome caused by mitochondrial DNA deletion. Doc Ophthalmol 1992; 82:73-9.

28. Reichenbach J, Schubert R, Horvàth R, et al. Fatal neonatal-onset mitochondrial respiratory chain disease with $\mathrm{T}$ cell immunodeficiency. Pediatr Res 2006; 60:321-6.

29. Woei-A-Jin FJ, van Breemen MS, Brand A, Brouwer RE. [Reversible thrombocytopenia and polyneuropathy: the pleiotropic aspects of hypothyroidism]. Ned Tijdschr Geneeskd 2010; 154:A963. Dutch.

30. Norddahl GL, Pronk CJ, Wahlestedt M, et al. Accumulating mitochondrial DNA mutations drive premature hematopoietic aging phenotypes distinct from physiological stem cell aging. Cell Stem Cell 2011; 8:499-510. 
31. Barth PG, Van den Bogert C, Bolhuis PA, et al. X-linked cardioskeletal myopathy and neutropenia (Barth syndrome): respiratory-chain abnormalities in cultured fibroblasts. J Inherit Metab Dis 1996; 19:157-60.

32. Boztug K, Klein C. Novel genetic etiologies of severe congenital neutropenia. Curr Opin Immunol 2009; 21:472-80.

33. Muraki K, Nishimura S, Goto $Y$, et al. The association between haematological manifestation and mtDNA deletions in Pearson syndrome. J Inherit Metab Dis 1997; 20:697-703.

34. Finsterer J, Höger F. Multi-system mitochondrial disorder with recurrent steroid-responsive eosinophilia. Rheumatol Int 2009; 30:135-9.

35. Sasarman F, Nishimura T, Thiffault I, Shoubridge EA. A novel mutation in YARS2 causes myopathy with lactic acidosis and sideroblastic anaemia. Hum Mutat 2012; 33:1201-6.

36. Fleming MD. Congenital sideroblastic anaemias: iron and heme lost in mitochondrial translation. Hematology Am Soc Hematol Educ Program 2011; 2011:525-31.

37 Cazzola M, Invernizzi R. Ring sideroblasts and sideroblastic anaemias. Haematologica 2011; 96:789-92. 